\title{
Kansei engineering as a tool for the design of in-vehicle rubber keypads
}

\author{
Joana Vieira $^{\text {a, }}{ }^{*}$, Joana Maria A. Osório ${ }^{b}$, Sandra Mouta a , Pedro Delgado ${ }^{\text {, }}$ \\ Aníbal Portinha ${ }^{c}$, José Filipe Meireles ${ }^{d}$, Jorge Almeida Santos ${ }^{\text {a, b, e }}$ \\ a Centro de Computação Gráfica, Campus of Azurém, 4800-058, Guimarães, Portugal \\ b University of Minho, Centro Algoritmi, Campus of Azurém, 4800-058, Guimarães, Portugal \\ ${ }^{c}$ BOSCH Car Multimedia, Rua Max Grundig, 35, Lomar, 4705-820, Braga, Portugal \\ ${ }^{\mathrm{d}}$ University of Minho, Department of Mechanical Engineering, Campus of Azurém, 4800-058, Guimarães, Portugal \\ e University of Minho, Department of Basic Psychology, Campus of Gualtar, 4710-057, Braga, Portugal
}

\section{A R T I C L E I N F O}

\section{Article history:}

Received 10 May 2016

Received in revised form 20 November 2016

Accepted 26 December 2016

\section{Keywords:}

Kansei engineering

Rubber keypads

Automotive HMI

Snap ratio

\begin{abstract}
A B S T R A C T
Manufacturers are currently adopting a consumer-centered philosophy which poses the challenge of developing differentiating products in a context of constant innovation and competitiveness. To merge both function and experience in a product, it is necessary to understand customers' experience when interacting with interfaces. This paper describes the use of Kansei methodology as a tool to evaluate the subjective perception of rubber keypads. Participants evaluated eleven rubber keys with different values of force, stroke and snap ratio, according to seven Kansei words ranging from "pleasantness" to "clickiness". Evaluation data was collected using the semantic differential technique and compared with data from the physical properties of the keys. Kansei proved to be a robust method to evaluate the qualitative traits of products, and a new physical parameter for the tactile feel of "clickiness" is suggested, having obtained better results than the commonly used Snap Ratio. It was possible to establish very strong relations between Kansei words and all physical properties. This approach will result in guidance to the industry for the design of in-vehicle rubber keypads with user-centered concerns.
\end{abstract}

๑) 2017 Elsevier Ltd. All rights reserved.

\section{Introduction}

Industrial facilities producing keypads have to deal with design requests and demands regarding several mechanical and/or technical properties of rubber keypads. These properties include actuation force, contact force, stroke and snap ratio. However, the guidelines provided by the industry are rarely based on empirical metrics of consumers' perceptions, or are kept confidential when a more systematic validation is applied.

Customers of a given service or product often provide feedback using emotional and subjective descriptors. For example, customers' reviews and comments include words such as "Fantastic", "Cheap" or "Comfortable" related to a given product. However, the objective quantification of what exactly is a cheap-looking car seat, an unpleasant button or a comfortable driving wheel is seldom approached in the literature. Is there a quantitative correlate to all

\footnotetext{
* Corresponding author.

E-mail address: joana.vieira@ccg.pt (J. Vieira).
}

these subjective descriptors? Nowadays, more and more manufacturers adopt a consumer-centered philosophy (Nagamachi and Lokman, 2010), and investigate customers' qualitative demands in order to apply them in their production plan (Yang et al., 1999). The popular phrase stating that "we no longer buy products, we buy experiences", emphasizes the idea that, to be purchased, products need to add something more to their functionality (Norman, 2004), and that something must differentiate them from all other products with the same function.

The concept of experience in itself has evolved from a collection of practical acts resulting in a given competence or skill (Dewey, 2005) into something holistic, built on contextual and personal relations. In sensory terms, the look and feel of a product might be as determinant in using it, as its functional possibilities (Wright and Mccarthy, 2005). Considering this new focus, some authors state that, to succeed, manufacturers must benefit aesthetics and subjective quality of products as much as properties like reliability and physical quality (Liu, 2003; Rösler et al., 2009).

In the automotive industry, context of the present study, there 
are deep concerns about the best way to address certain target groups or characteristics in order to evoke given emotions, feelings or subjective experiences. At the same time, it would also be important to know where and what to address exactly when vague complaints arrive from customers. The latter is one of the main motivations for the present study in the specific context of the construction of rubber keypads, as clients communicate having "unpleasant" or rubber keys they "dislike" for some reason. Thus, the goal of this study is to analyse the relations between the physical properties of rubber keypads used inside the vehicles, and the subjective perceptions they evoke. As a result, the subsequent data would serve to create guidelines for the tactile feel of interaction elements such as auto radios or other devices using rubber keys, also demonstrating how an experimental approach can be used to provide a robust support for manufacturing guidelines.

\subsection{Kansei engineering}

Significant concerns have been expressed about the lack of engineering and scientific methods to study aesthetics concepts. Liu (2003) suggests most decisions are based on the "educated guesses, talents or gut-feelings" (p. 1273) of product designers, and a more systematic approach should be used. As an example, psychophysical methods could quantify fine aesthetics distinctions among given product dimensions. Other methodologies, like Kansei Engineering, might be considered an answer to this appeal, as its procedures are systematic and statistically validated.

Kansei Engineering (KE) emerged in Japan in the 1970s with the purpose of connecting the customers' affective responses to the design process of products, in an attempt to translate emotions into measurable and physical design specifications. Whenever a customer intends to buy a product, a preconceived positive or negative image comes to mind. The Japanese word Kansei refers to the intuitive mental action of the person who feels some sort of impression from an external stimulus (Nagamachi and Lokman, 2010). This approach was developed in order to maximize customers' satisfaction with their purchases (Nagamachi, 2005). As today's customers grow more informed, demanding and sophisticated, the focus on Kansei might just be the differentiating factor.

There are several methods for performing Kansei Engineering (Type I, II, III, Hybrid, and Virtual), differing slightly in the number of evaluations or in the form of presenting items and analysing data (Nagamachi and Lokman, 2010). One of the most commonly used is a Type II-based method, adapted by Schütte (2002) into a general KE procedure. This procedure has less assessments with users, but was validated in several applications and industrial case-studies, like chocolate exteriors (Schütte, 2013), rocker switches (Schütte and Eklund, 2005) and wood flooring (Nordvik et al., 2009).

The model proposes the definition of the domain or target, which should be indicative of the target user and the product group (Dahlgaard et al., 2008). The following step concerns spanning the semantic space, by collecting a large number of words or expressions that could be used to describe the domain. The number of words could go up to 800 descriptors related to the target (Nagamachi and Lokman, 2010). These are the low-level Kansei words which will later be organized into high-level Kansei words, using simple categorization and group consensus, or methods like factorial analysis. In parallel, the space of properties should also be collected, consisting in physical product properties to be evaluated.

The evaluation experiment consists in presenting representative examples of the product and evaluating each according to all selected High-Level Kansei words which are usually presented in a Likert or continuous scale with two words on each end, and participants' answers are recorded. Finally, relations between the semantic space (Kansei words) and the space of properties (physical characteristics) are analysed, using statistical tools.

As an example of a possible outcome of $\mathrm{KE}$, to evaluate the "roominess" and the "oppressiveness" of the interior of a vehicle, Tanoue et al. (1997) managed to identify that factors such as colour and shape influenced the perception of the participant, but more specifically, both dimensions were affected by the windshield rake angle, the distance between head liner and hip point, and the distance from the driver to the instrument cluster. Also in an invehicle study, Jindo and Hirasago (1997) applied KE to understand the best design for speedometers and driving wheels.

\subsection{Semantic differential technique}

The Kansei is evaluated using the Semantic Differential technique, developed by Osgood and colleagues (1957). The authors proposed that the human's mind image of a person, object or service spanned between two antonyms, like Good-Bad, and that a straight line connecting both words could be used to indicate where an opinion would be in the continuum or scale. The technique could also be used to measure the subjective perception of physical properties, like weight or brightness. Kansei Engineering thinks similarly, believing words could be used as sensors for emotions, only that it uses opposites instead of antonyms, using one word to deny the other, like elegant-inelegant (Nagamachi and Lokman, 2010).

The number of choices between the two words is flexible in Kansei Engineering, and these scales can range between 3, 5, 7, 9 and 11 levels presented in a Likert-scale style. Some authors use different scales obtaining equivalent results, such as the Visual Analogue Scale (VAS) (Dahlgaard et al., 2008). The VAS consists of a $100 \mathrm{~mm}$ long horizontal or vertical line, and is a reliable method commonly used for the evaluation of pain intensity (Bijur et al., 2001; DeLoach et al., 1998), but also applied in other contexts due to its simplicity. Each endpoint of the line is labelled with one descriptor representing the extremes of a continuum ( $\mathrm{Vu}$ and Proctor, 2011). Participants indicate somewhere in the line where their judgement, opinion or perception is located, and the score is calculated by measuring the distance from the extremity on the left. Myles and colleagues demonstrated that the VAS score has ratio scale properties, and that changes in the VAS score reflect relative changes in the magnitude of what is under evaluation.

\subsection{Physical parameters of automotive push-switches: F1, F2, stroke and snap ratio}

Automotive push-switches - the push buttons of keypads or keyboards - use a variety of switch technologies, mostly mechanical. The silicone rubber keypads (elastomeric keypads) are the most commonly used in in-vehicle multimedia products, as they are a low cost and reliable switching solution. Each button of the keypad has a specific geometry that enables the collapsible behaviour of the angled webbing around a switch centre. Fig. 1 presents an example of an elastomeric key and its successive positions during the application of pressure. When the switch is pressured, the webbing, initially uniform, deforms to position s1 and secondly collapses to produce a tactile response, position s2. As long as the key is held, the carbon centre completes the circuit through the contact of a carbon pill with the PCB (Printed Circuit Board). The sC corresponds to the final position of the key that includes the collapsing of the membrane and the deformation of its top. When pressure is removed from the key, the webbing returns to its neutral position with positive feedback. Its overlay has led to advances in technology, including the use of hard plastic key tops assembled to a rubber keypad resulting in a general design with an enhanced tactile response. 


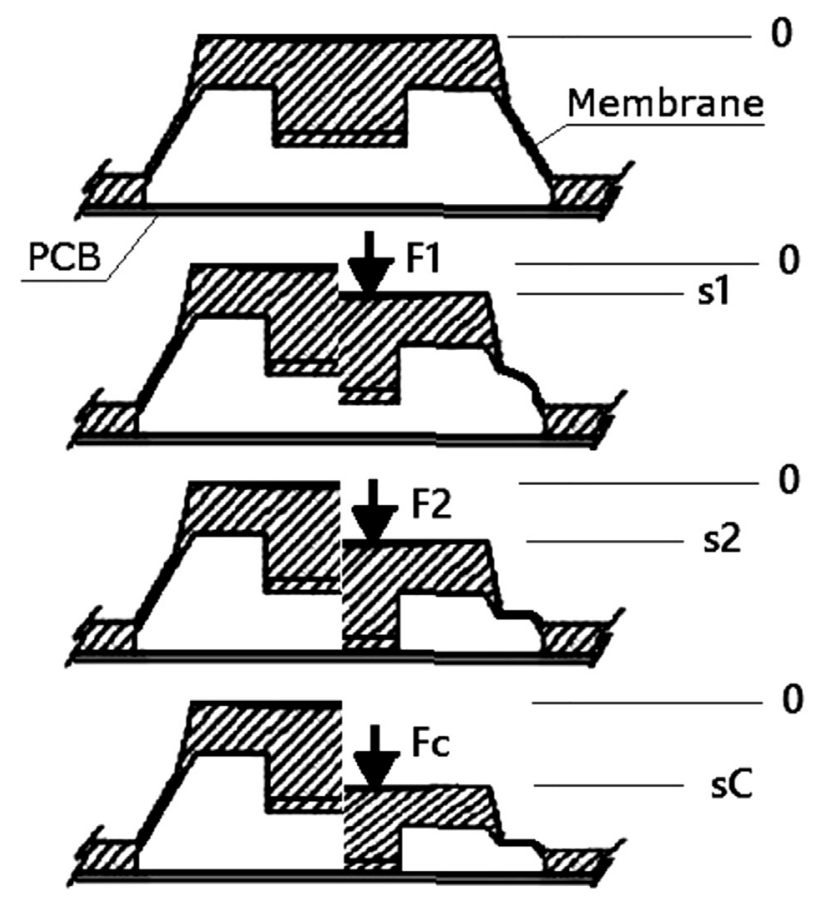

Fig. 1. Example of a key section.

The key stiffness is a function of material softness (silicone rubber) and membrane cone geometry such as thickness, length, and angle. Since the key top is only supported by the edge of the cone, the response to pressing its top is always different, and this movement may result in different tactile sensations. The membrane shape and size of the rubber key can be geometrically defined with respect to any actuation force and tactile feel. A work by Lee et al. (2015) provides an example where the volume of the membrane was minimized in order to meet the required constraints of resistance force. Thus, one of the key features will be the stroke, or the distance from the contact surface on a rubber switch carbon contact to an electrode pattern on the PCB (ARC-USA, 2009).

The actuation force (F1) is another important key parameter. F1 is the force required to collapse the membrane of a rubber switch (ARC-USA, 2009). With both of these features, it is possible to predict the haptic feedback of a keypad's switch membrane. The snap ratio, or the click ratio as it is often called, is another very popular feature that affects the tactile feel of the operator. The snap ratio can be calculated by the formula (F1-F2)/F1, where $\mathrm{F} 1$ is the actuation force corresponding to s1 and F2 is the contact force, corresponding to $\mathrm{s} 2$, the force required to maintain rubber-switch contact with a PCB.

It is possible to obtain the force versus displacement characteristic of each key. Fig. 2 has an example of a curve diagram of the force applied versus stroke described by the top key when pressured. The static force applied to the key is usually determined by measuring with a load cell the reaction force in the top key. Simultaneously, the stroke of the top key is measured using a displacement transducer like a LVDT (Linear Variable Displacement Transducer). All the results of Fig. 2 are presented in static forcedisplacement curves.

These static force-displacement graphs have been the most interesting method to compare switch key characteristics. The curve shows a nonlinear relationship between key force and its displacement according the rubber material characteristics. Between F1 and F2 the membrane collapses to position s2 to produce a tactile response which leads to the contact of a carbon pill with

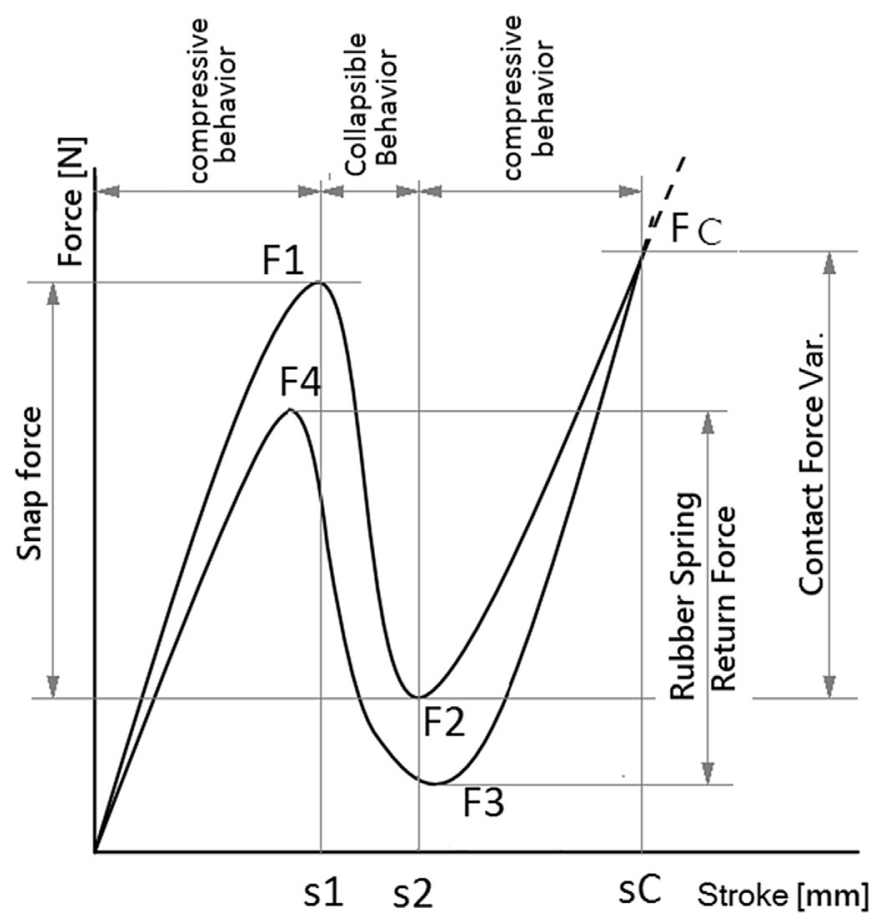

Fig. 2. Stroke and reaction force of a switch key.

the PCB with the force F2. This force can be increased to FC, depending of inertial finger actuation movement. The force displacement characteristic exhibits a regime of negative stiffness between F1, snap point and F2, contact force. The difference (F1-F2) is the $\Delta \mathrm{F}$.

As soon as the key is liberated, the top key movement is reversed. The force measured is now minor than when the key is pressed down. The difference (F4-F3) is the spring return force that positions the key at beginning. The force measured is now minor than when the key was pressed down. This study will focus on the following variables: F1 or actuation force, F2 or contact force, Stroke and Snap Ratio.

\subsection{The subjective evaluation of keypad interfaces}

KE is widely applied to products and interfaces for evaluating the subjective perception of users. Nevertheless, some areas remain understudied as the application of the method is not trivial. One of these cases is the haptic perception of keys, switches or buttons, as the KE must be developed using consistent and objectively measured physical properties of force, stroke and snap ratio. Snap ratio is derived from a formula which encompasses actuation and contact forces, and represents the tactile feel obtained when pressing a key.

Kosaka and colleagues (2005) applied KE in the design of keyboard switches using one switch simulator that arbitrarily generated force characteristics (initial, peak, drop and ending reaction force). Variables like stroke and snap ratio were not considered. The Kansei words used during evaluation were deep, clear, smooth, stiff, initially smooth, arriving shock and clicking, which were presented in a semantic differential scale. The procedure demonstrated that the feeling of depth increased with the initial force and decreased with a growing ending force, and that the clicking sensation decreased when the ending force increased. The results pointed to an almost linear relation between forces and Kansei. Based on them, a neural network was built which 
automatically designed four kinds of reaction forces. This tool was to be used in future design processes. In a different set-up, Hatzfeld and colleagues (2010) did not use real examples of haptic elements, but used household light switches with five force-displacement characteristics. The objective of their study was to select the best perception-based method to predict user ratings of haptic control elements (weighted or non-weighted). The evaluation pairs used were soft-hard, crisp-worn out, weak-strong, smooth running-roughrunning, gentle-bumpy, reliable-unreliable, fragile-robust and pleasing-displeasing. Among others, the results suggested that the parameter click-ratio, commonly used in the industry as a quality control measure, was not very useful in predicting user ratings and should be replaced with a different metric.

In the automotive context, Rösler and colleagues (2009) tested a series of different in-vehicle push buttons or rotary dials. Participants rated them according to pairs of words related to hardnesssoftness, stiffness and looseness, unreliability-reliability, and originality-conventionality. The authors found that hardness-softness could be predicted by the actuation force of the forward movement or the backward movement - contact resistance; and stiffness-looseness could be predicted by the button's stroke, meaning that the longer it was, the heavier, thicker and longer was it perceived. In a similar study, but considering the testing environment, Wellings et al. (2010) compared the perception of switches inside and outside their context-of-use, in this case, inside and outside the vehicle. Owners of luxury saloons evaluated the feel of push switches according to touch, visual and audio-related words. The pairs of adjectives used were heavy-light, impreciseprecise, cheap-expensive, noisy-quiet, refined-unrefined, clickysmooth, pleasant-annoying, loose-tight, flimsy-solid, interesting-dull, old fashioned-modern. Results demonstrated that participants were able to perceive meaningful differences between switches, and were congruent in their preferences. The authors refer there are physical properties that influence this clear grouping of preferences, and reveal interest in exploring them. No significant differences were found between the evaluations made in different contexts, suggesting that a less immersive test environment also yields accurate results. Three factors explained a high percentage of the total variance: Image, Build Quality and Clickiness. This suggested that customers considered other properties when evaluating haptic criteria such as usability, visual appearance and sound quality.

\subsection{Aim}

The main aim of this study is to apply Kansei methodology in a controlled, laboratorial context in order to correlate users' subjective perceptions with the physical properties of the keys used in invehicle settings. Ultimately, we seek to set the bases of consumeroriented guidelines for the production of keys for in-vehicle interfaces, validated by a systematic and experimental approach. Additionally, and keeping previous research in mind, the concept of tactile feel translated by the Snap or Click Ratio, will also be examined. Industry guidelines take this parameter as directly affecting the tactile feel of a key (ARC-USA, 2009), and it is often used as a quality control measure. Nevertheless, previous studies (Hatzfeld et al., 2010) have demonstrated that this parameter should be reconsidered as predictor of user ratings. Hence, our study intends to determine which physical property evokes which subjective perception, and in doing so, evaluate the predictive capacity of the chosen physical parameters.

\section{Material and method}

The selected KE procedure was the previously described Type II- based, general model proposed by Schütte (2002), due to its applicability and validation in several industry case studies. Linear regressions will later be used to establish relations between the selected Kansei words and the physical properties.

\subsection{Domain and semantic space}

The semantic space was gathered among two distinct populations who followed the same collecting instructions. One group was constituted by researchers and academics from mechanical engineering, experimental psychology and ergonomics. The other group was constituted by workers at the stakeholder's facilities. They were given simple instructions about the type of words that could be used. The domain under which all contributors had to propose related words was "haptic feedback of key matrixes with different force, stroke and snap ratio, with similar appearance, in a laboratorial context." Words could be adjectives or other grammatical classes, and expressions were also accepted.

A total of 116 words were collected via e-mail, which were afterwards manually organized (Schütte, 2005) into consistent groups by the authors. Out of these groups, higher-level Kansei words were selected to represent the concept in question. This selection, achieved in presential meetings, was done by both contributing groups (researchers and workers at the stakeholder's facilities). Initially, five groups were proposed, with the following high-level Kansei words: Global Evaluation; Depth; Feedback; Force and Stability (Table 1). Nevertheless, for clarification purposes, the group opted to unfold these words into seven pairs of words to represent the semantic space.

The selected semantic space consisted mainly on the perception of physical attributes, being the most subjective pairs of words related with the pleasantness and clickiness of the presented keypads.

All pairs of words were presented in an analogue visual scale, in one continuum ranging from 0 to $100 \mathrm{~mm}$ (without numbering).

\subsection{Space of properties and samples}

The type of platform used for the experiment is presented in Fig. 3. Two of these platforms were used, each one composed by 36 buttons on a $6 \times 6$ matrix, with different levels of force (F1 and F2), stroke and snap ratio. Each button had a LED-light on top to indicate which button should be pressed.

The platform was set $5^{\circ}$ from the vertical axis and each key was randomly assembled with a specific silicone rubber. The platforms had different rubber key compositions, but all the rubber keys were included between the values: Force of $1.47 \mathrm{~N}-4,12 \mathrm{~N}$, Stroke of $0,97 \mathrm{~mm}$ to $1,78 \mathrm{~mm}$ and Snap Ratio of $8 \%-64 \%$.

Eleven keys were selected out of the two $6 \times 6$ key matrixes. These were chosen according to representative values of Force, Stroke and Snap Ratio, in order to have the largest range of values between all variables. Table 2 presents the values of all the selected keys for the space of properties.

Table 1

High-level Kansei words from the semantic space and the corresponding pairs of words used for the evaluation.

\begin{tabular}{ll}
\hline Global Evaluation & Unpleasant - Pleasant \\
Depth & Short - Long \\
Feedback & Without/With sharp click \\
Force & Smooth - Hard \\
& Not very - Very strong \\
Stability & Fragile - Robust \\
& Loose -Stiff \\
\hline
\end{tabular}




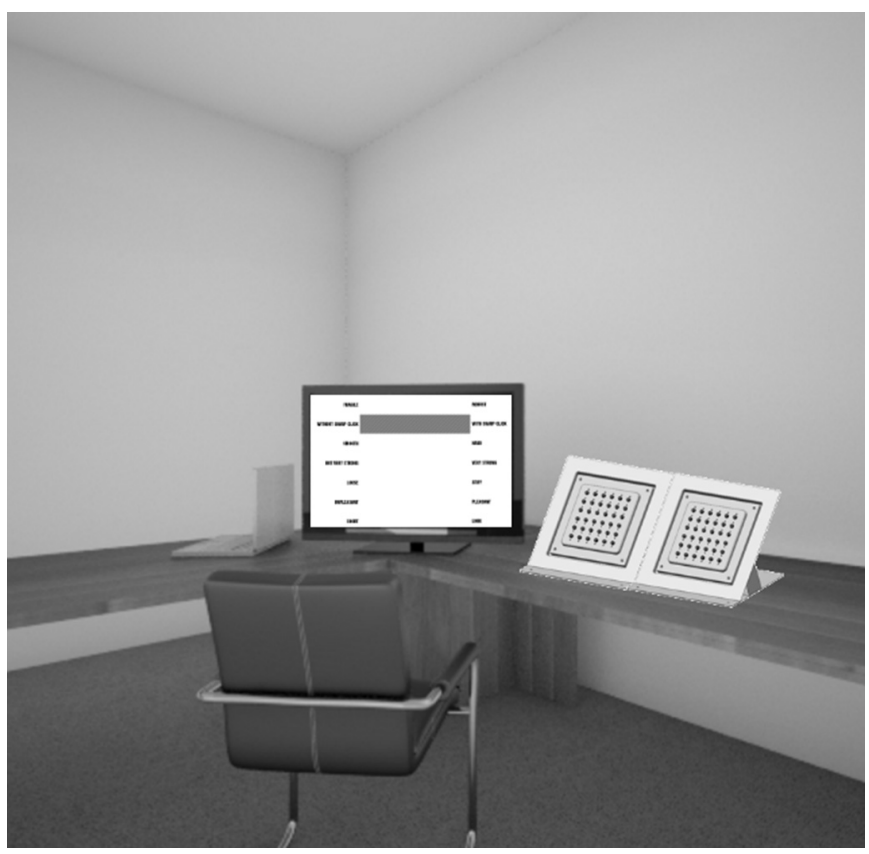

Fig. 3. Set-up of the experiment. The participant was seated in front of a touch screen and the two key platforms. In the touch screen, all seven pairs of Kansei words were displayed, and the pair currently under evaluation was highlighted with a green bar. The participant should touch a point along the scale, depending on his or her evaluation of the key.

Table 2

Characteristics of all eleven keys selected for the space of properties according to Actuation Force (F1), Contact Force (F2), Stroke and Snap Ratio.

\begin{tabular}{lllll}
\hline Keys & F1 $(\mathrm{N})$ & F2 $(\mathrm{N})$ & Stroke $(\mathrm{mm})$ & Snap Ratio $(\%)$ \\
\hline K1 & 3,67 & 3,37 & 1,05 & 8,02 \\
K2 & 4,12 & 3,33 & 1,36 & 19,05 \\
K3 & 2,82 & 2,39 & 1,05 & 15,28 \\
K4 & 2,08 & 1,47 & 0,97 & 29,25 \\
K5 & 1,59 & 0,84 & 1,07 & 46,91 \\
K6 & 1,47 & 0,98 & 1,21 & 33,33 \\
K7 & 1,47 & 0,69 & 1,25 & 53,33 \\
K8 & 3,57 & 2,14 & 1,64 & 40,11 \\
K9 & 3,06 & 1,51 & 1,78 & 50,64 \\
K10 & 3,55 & 2,49 & 1,76 & 29,83 \\
K11 & 1,47 & 0,53 & 1,05 & 64,00 \\
\hline
\end{tabular}

\subsection{Participants}

Twenty-eight volunteers participated in the study ( 12 female, 16 male), with ages ranging from 22 to 59 years $(M=33 ; S D=8)$. All participants had a valid driver's license, driving annually on average $29.346 \mathrm{~km}(\mathrm{SD}=32.298)$. All but two had the right hand as dominant hand.

\subsection{Apparatus and procedure}

The experiment was set in a small and quiet room (Fig. 3). After signing an informed consent, participants were seated in front of a table with two $6 \times 6$ key matrixes platforms, each next to the other.

The two key matrixes platforms were connected to a Lenovo ThinkCentre M92p running on Windows 8 (Intel Core i5-3470T) to collect participants' answers via an Arduino Mega. A Dell E2014T touch screen was used to present the custom-made interface with the visual analogue scale, and to register the participant's answers.

On the touch screen, all seven pairs of words were presented on the extremities of a continuous scale, and the pair currently under evaluation was highlighted with a green bar. The participant was instructed to touch a point along the scale, depending on his or her evaluation of the key.

The final output of the system showed the number and characteristics of the pressed key (F1 and F2 (N), stroke (mm) and snap ratio (\%)), along with the value attributed by the participant in the analogue visual scale $(0-100 \mathrm{~mm})$.

The presentation procedure was selected after a pilot experiment in which three different methods of presenting the keys and respective pairs of words were tested. The first method consisted in presenting one pair of words and evaluating all keys according to it; the second method consisted in presenting the same key and evaluating all pair of words according to the key; and the third method consisted in changing both the key and the pair of words after each evaluation. In this method of presentation, for instance, the first key could be evaluated for "Fragile - Robust" and the following key would be evaluated for "Short-Long". In all methods, the order of presentation of keys and words was random. The method which gathered more consistency between and within participants was the third method, and therefore it was the selected one for this study.

The eleven keys were evaluated for the seven pairs of words. For each evaluation, a red LED would light above the randomly selected key, indicating the participant she or he should press that key. The participant was instructed to press each key only once, using always the same finger.

Simultaneously, the analogue visual scale for one pair of words, also randomly selected, was presented on the touch screen. After pressing the key, the participant should indicate in the touch screen where, in the analogue visual scale, would the pressed key fit. No instruction was given regarding the hand with which the interaction with the touch screen should be made. After each trial, the participant should place the right hand on the table, and wait for the activation of the next key.

In the test session, after a brief training period, all participants evaluated each one of the eleven keys according to the seven pairs of words twice, resulting in 154 evaluations in one session with one break. The total procedure lasted $30 \mathrm{~min}$.

\section{Results}

After screening the data for acceptable levels of stability and within-subject consistency, outliers were identified and two participants were removed from the sample. The first and second evaluations of twenty-six participants were then pooled and averaged for further analysis for each key and for each Kansei pair of words (Table 3).

All relations between physical properties and Kansei pairs of words were explored using linear regression models with logarithmic transformations of the independent variable $(\log 10)$, $\mathrm{Y}=\mathrm{a} 1 \mathrm{X} 1+\mathrm{a} 2 \mathrm{X} 2+\mathrm{a} 3 \mathrm{X} 3+\mathrm{a} 4 \mathrm{X} 4+\mathrm{b} 0$, where $\mathrm{a} 1=\mathrm{F} 1, \mathrm{a} 2=\mathrm{F} 2$, a3 = Stroke, a4 = Snap Ratio and b0 = Constant.

Results were mapped for all Kansei words according to the variables F1, F2, Stroke and Snap Ratio. General results indicate that all Kansei words were predicted by at least one of the physical variables.

Later analysis included a Principal Component Analysis (PCA) to better understand which main factors contributed to the subjective perception of the participants.

\subsection{Actuation and contact forces (F1 and F2)}

A summary of all results is presented in Table 4 . It reports the values of $\beta$, the gradient of the regression line; $R^{2}$, how much 
Table 3

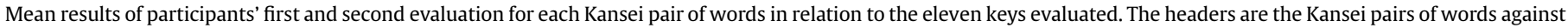

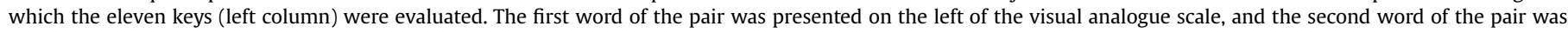
presented on the right side of the scale.

\begin{tabular}{|c|c|c|c|c|c|c|c|}
\hline & Short - Long & Unpleasant Pleasant & Fragile - Robust & $\begin{array}{l}\text { Not very } \\
\text { Very strong }\end{array}$ & Loose-Stiff & $\begin{array}{l}\text { Without } \\
\text { With sharp click }\end{array}$ & Smooth - Hard \\
\hline K1 & 30,41 & 21,87 & 71,45 & 70,12 & 82,53 & 20,67 & 81,40 \\
\hline $\mathrm{K} 2$ & 39,35 & 35,29 & 71,89 & 76,34 & 76,01 & 57,13 & 76,87 \\
\hline K3 & 34,56 & 31,30 & 68,96 & 64,69 & 76,09 & 34,13 & 74,15 \\
\hline K4 & 33,34 & 46,36 & 56,03 & 48,02 & 55,46 & 43,68 & 51,54 \\
\hline K5 & 31,67 & 55,07 & 39,18 & 30,42 & 38,36 & 49,26 & 36,12 \\
\hline K6 & 43,81 & 45,19 & 37,40 & 30,60 & 40,35 & 44,52 & 41,91 \\
\hline K7 & 43,35 & 63,07 & 35,41 & 24,98 & 34,9 & 45,41 & 27,26 \\
\hline K8 & 61,85 & 62,52 & 71,36 & 59,88 & 63,82 & 78,37 & 60,84 \\
\hline K9 & 66,52 & 56,83 & 72,81 & 59,04 & 59,86 & 76,35 & 59,71 \\
\hline K10 & 66,71 & 46,31 & 69,52 & 64,06 & 70,53 & 64,78 & 62,51 \\
\hline K11 & 34,97 & 61,96 & 31,56 & 22,10 & 36,74 & 50,92 & 28,47 \\
\hline
\end{tabular}

Table 4

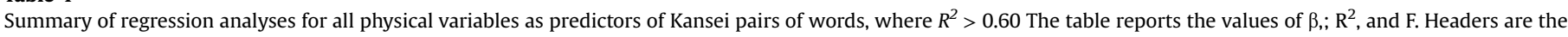

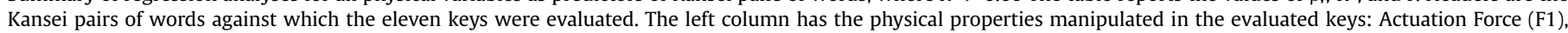
Contact Force (F2), Stroke, Snap Ratio, and a new variable, DeltaF.

\begin{tabular}{|c|c|c|c|c|c|c|c|c|}
\hline & & Short Long & Unpleasant Pleasant & Fragile Robust & $\begin{array}{l}\text { Not very } \\
\text { Very strong }\end{array}$ & $\begin{array}{l}\text { Loose } \\
\text { Stiff }\end{array}$ & $\begin{array}{l}\text { Without } \\
\text { With sharp click }\end{array}$ & Smooth Hard \\
\hline \multirow[t]{3}{*}{ F1 } & $\beta$ & & & $0.97^{* * *}$ & $0.99^{* * *}$ & $-0.93^{* * *}$ & & $0.91^{* * *}$ \\
\hline & $R^{2}$ & & & 0.94 & 0.99 & 0.87 & & 0.84 \\
\hline & $F$ & & & 133.5 & 727.9 & 60.02 & & 46.25 \\
\hline \multirow[t]{3}{*}{$\mathrm{F} 2$} & $\beta$ & & & $0.93^{* * *}$ & $0.93^{* * *}$ & $-0.97^{* * *}$ & & $0.97^{* * *}$ \\
\hline & $R^{2}$ & & & 0.86 & 0.86 & 0.94 & & 0.95 \\
\hline & $F$ & & & 53.99 & 56.41 & 153.3 & & 171.5 \\
\hline \multirow[t]{3}{*}{ Stroke } & $\beta$ & $0.96^{* * *}$ & & & & & $0.84^{* *}$ & \\
\hline & $R^{2}$ & 0.92 & & & & & 0.70 & \\
\hline & $F$ & 109.3 & & & & & $21.16^{* * *}$ & \\
\hline \multirow[t]{3}{*}{ Snap Ratio } & $\beta$ & & $0.96^{* * *}$ & & & $0.96 * *$ & & $0.82^{* *}$ \\
\hline & $R^{2}$ & & 0.93 & & & 0.67 & & 0.69 \\
\hline & $F$ & & 115.6 & & & $18.09^{* *}$ & & $20.42^{* * *}$ \\
\hline & $\beta$ & & & & & & $0.95^{* * *}$ & \\
\hline \multirow{2}{*}{$\begin{array}{l}\Delta \mathrm{F} \\
(\mathrm{F} 1-\mathrm{F} 2)\end{array}$} & $R^{2}$ & & & & & & 0.91 & \\
\hline & $F$ & & & & & & 88.41 & \\
\hline
\end{tabular}

${ }^{* * *} p<.001 .^{* *} p<.01$.

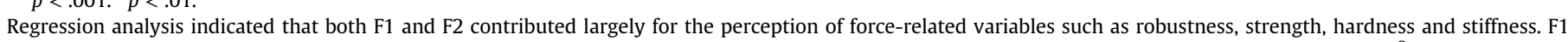

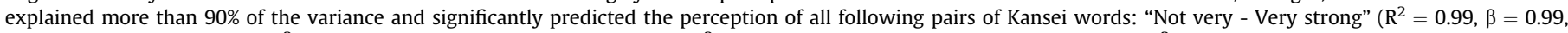

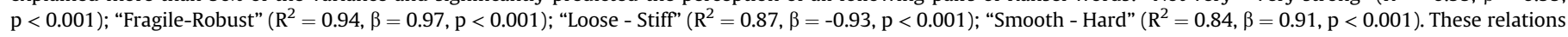

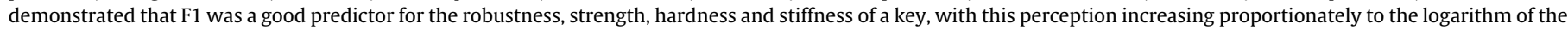
force.

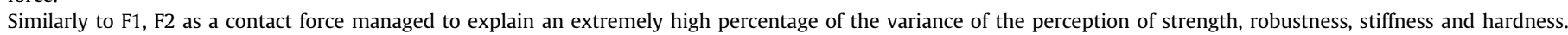

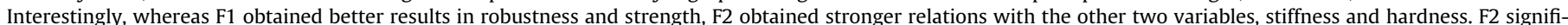

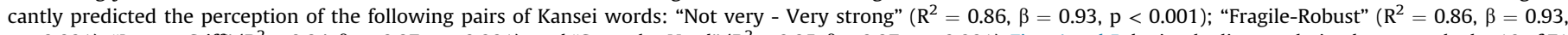

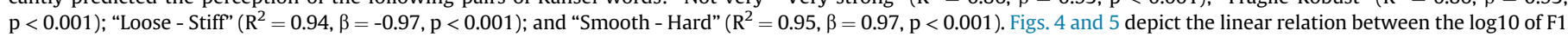
and F2 and these four pairs of Kansei words. The higher the actuation and contact forces, the more a key felt robust, strong, hard and stiff.

variance is explained by the model; and $F$, how much variability the model can explain relative to how much it cannot explain. (See Figs. 4 and 5

\subsection{Stroke}

The variable Stroke was the sole predictor of the "Short-Long" Kansei, demonstrating that as the stroke of the key increased, participants tended to evaluate the key as longer $\left(R^{2}=0.92\right.$, $\beta=0.96, p<0.001)$. Stroke was also the only predictor variable for the perception of a sharp click, explaining $70 \%$ of its variance $(\beta=0.84, p<0.01)$. F-ratio values also point towards the robustness of the predictive model for the sharp click perception ( $F$ $(1,9)=21,16, p<0.001)$. Fig. 6 depicts the relation between the two Kansei pairs "Short-Long" and "Without-With sharp click" and the $\log 10$ Stroke. As Stroke increased, the perception of length and sharpness in the click of a key also increased.

\subsection{Snap ratio}

Snap Ratio was the only predictor for the "Unpleasant Pleasant" Kansei pair, explaining 93\% of its variance, demonstrating that the perception of pleasantness increased with the Snap Ratio $(\beta=0.96, p<0.001)$. Similarly to the relations observed with F1 and F2, Snap Ratio was also able to predict the perception of the Kansei "Loose - Stiff" $\left(\mathrm{R}^{2}=0.67, \beta=0.96, \mathrm{p}<0.01\right)$ and "Smooth-Hard" $\left(R^{2}=0.69, \beta=0.82, p<0.001\right)$, although to a less extent than $F 2$ and F1. F-ratio values obtained suggest the proposed models for the perception of the Kansei "Loose-Stiff" and "Smooth-Hard" were able to predict more responses than the mean $(\mathrm{F}(1,9)=18.09$, $\mathrm{p}<0.01$ and $\mathrm{F}(1,9)=20.42, \mathrm{p}<0.001$, respectively). Fig. 7 depicts the relation between the three Kansei pairs and the log10Snap Ratio. As Snap Ratio increased, the perception of stiffness and hardness decreased, while the perception of pleasantness increased.

During this analysis, it was verified that the perception of 


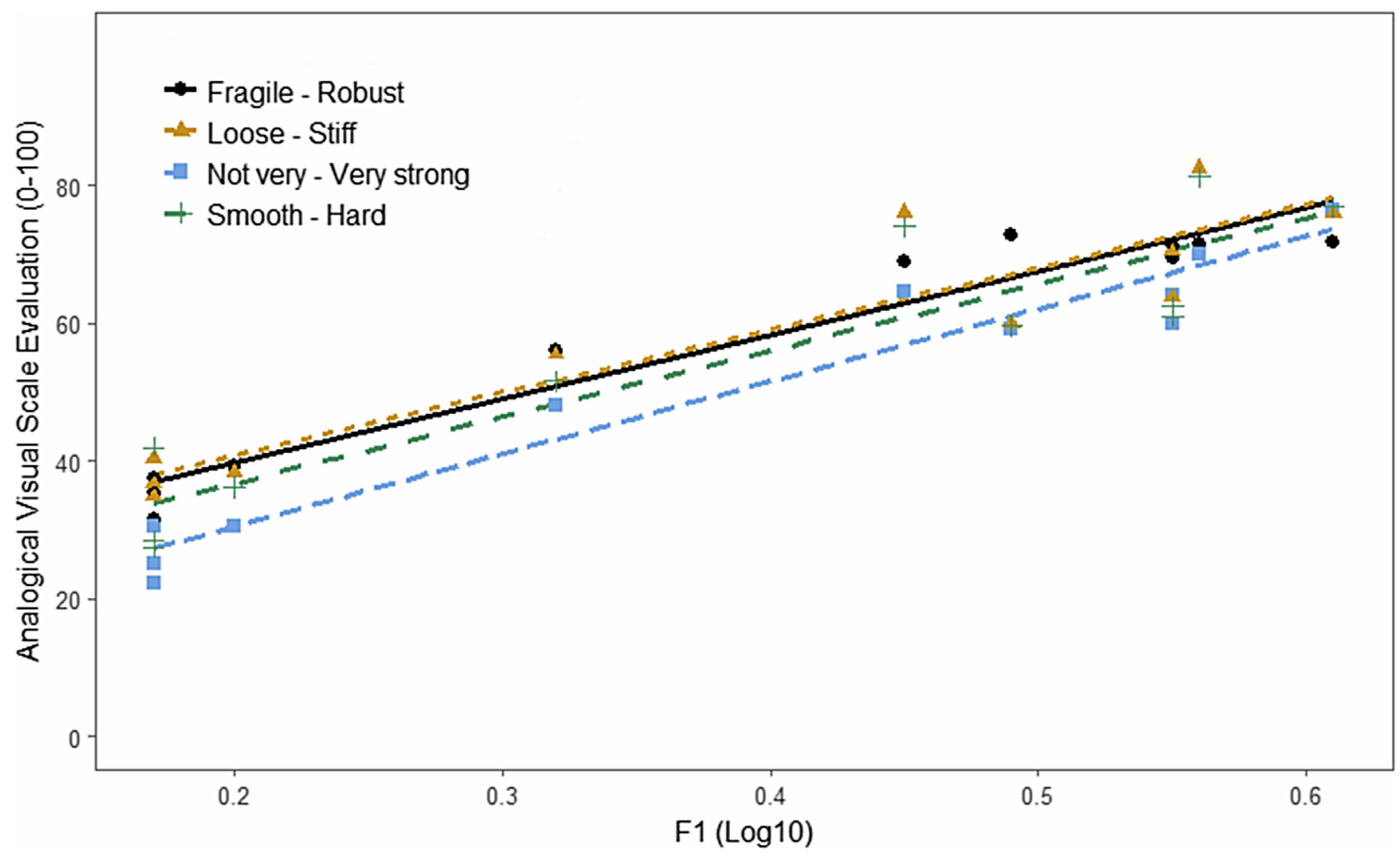

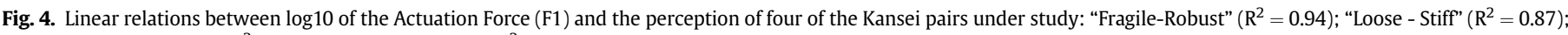
"Not very - Very strong" ( $\left.R^{2}=0.99\right)$; "Smooth - Hard" $\left(R^{2}=0.84\right)$.

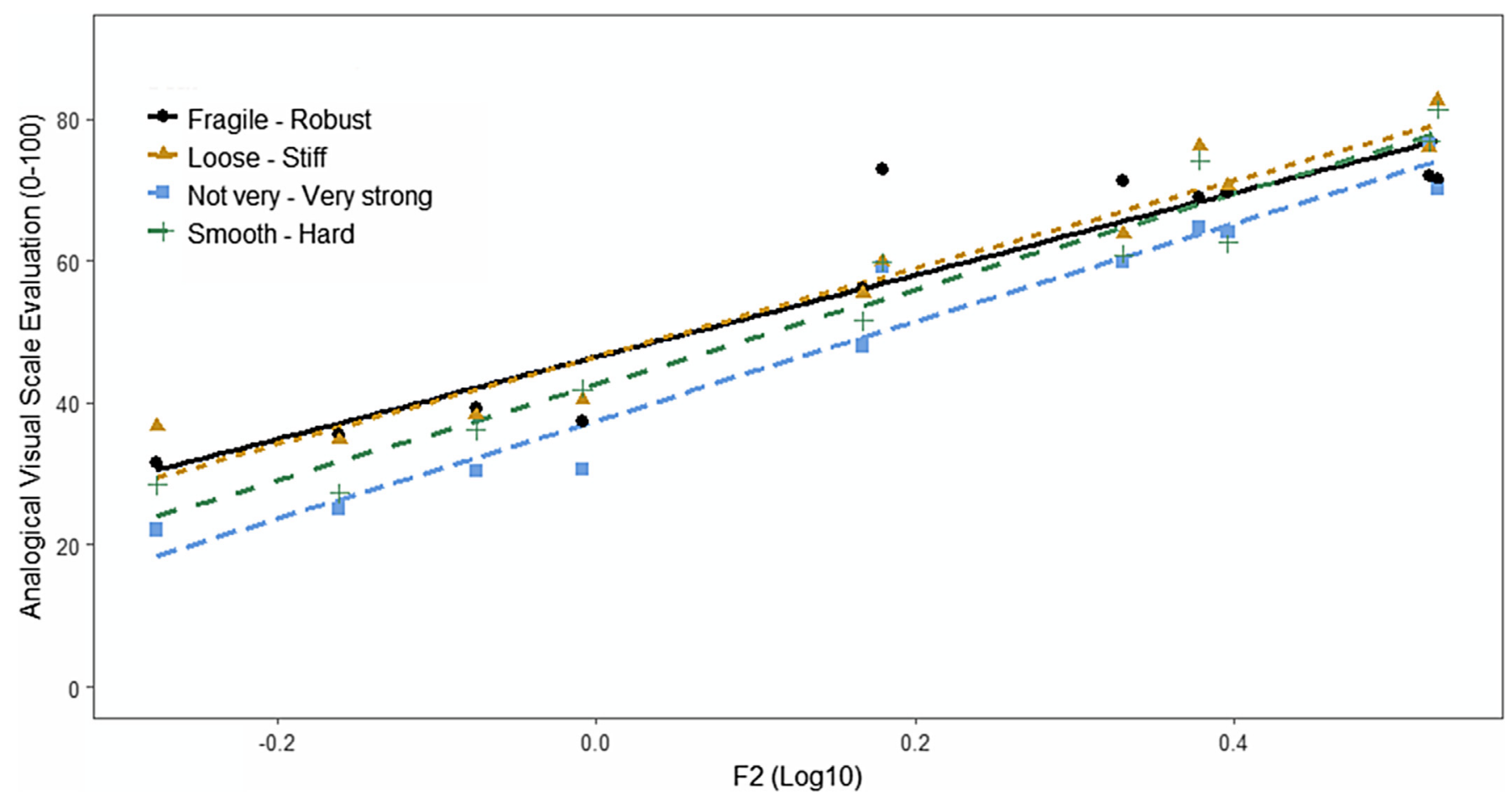

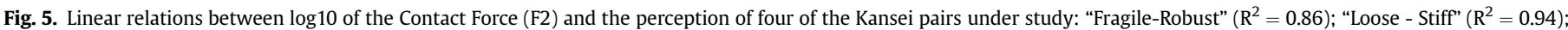
"Not very - Very strong" $\left(R^{2}=0.86\right)$; "Smooth - Hard" $\left(R^{2}=0.95\right)$. 


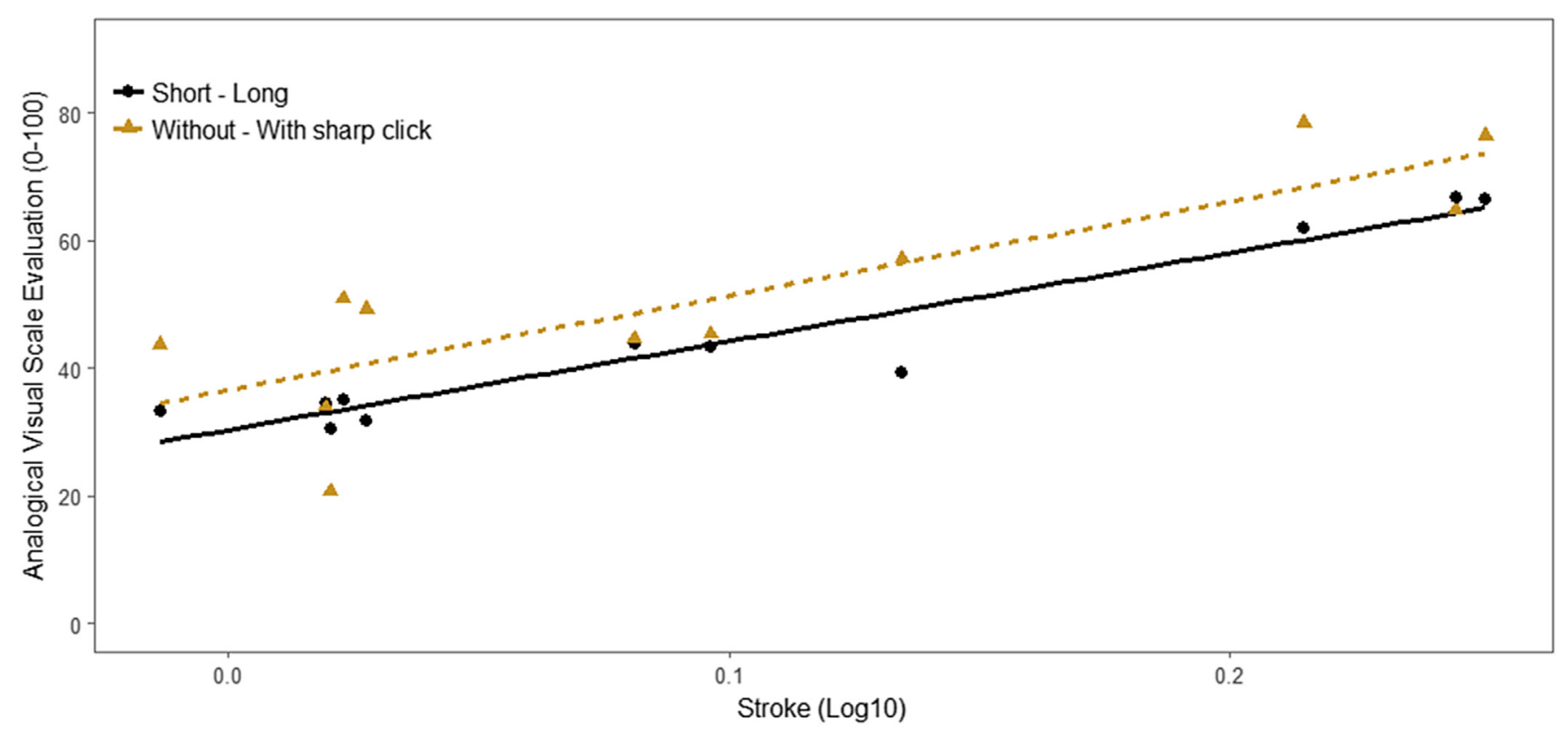

Fig. 6. Linear relation between $\log 10$ Stroke and the perception of "Short-Long" $\left(R^{2}=0.92\right)$ and "Without-With sharp click" $\left(R^{2}=0.70\right)$.

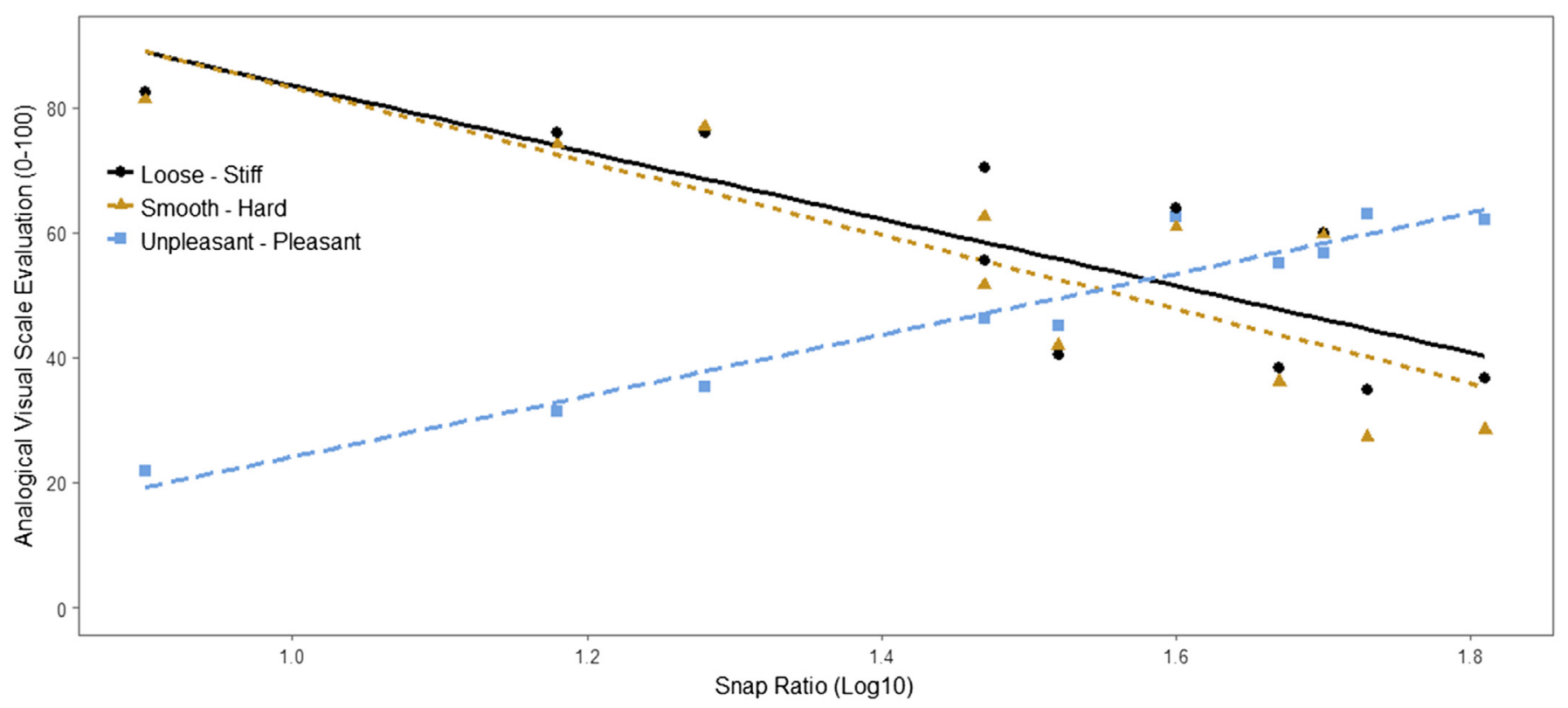

Fig. 7. Linear relation between $\log 10$ Snap Ratio and the perception of "Smooth - Hard" $\left(R^{2}=0.69\right)$, “Loose - Stiff" $\left(R^{2}=0.67\right)$, “Unpleasant-Pleasant" ( $\left.R^{2}=0.93\right)$.

clickiness was better explained by $\Delta \mathrm{F}$ than by Stroke, the only previously found predictor. $\Delta \mathrm{F}$ managed to explain $91 \%$ of the variation of the perception of the sharpness of a click (Table 4). This result suggests it is important to distinguish what is perceived as Clickiness from what is normally called click-ratio in the literature, referring to snap ratio. Fig. 8 presents the strong linear relation $\left(\mathrm{R}^{2}=0.91, \beta=0.95, \mathrm{p}<0.001\right)$ between the increase of the $\Delta \mathrm{F}$ and the increasing perception of the sharpness of a click.

\subsection{Principal Component Analysis}

To better understand the dimensions mediating the relations between participants' evaluations and the physical properties, a
PCA was conducted. This analysis employed the Kansei words for strength, stiffness, smoothness, pleasantness, length and clickiness, the primary physical properties of F1, F2 and Stroke, and the derived physical properties Snap Ratio and $\Delta F(F 1-F 2)$.

In the PCA (Fig. 9), all Kansei pairs of words were predicted by at least one of the independent variables, stressing the relevance of the semantic space used, and its strong relationship with the physical properties of the keys. Eigen values indicated that the first two factors explained almost $96 \%$ of the variance $(57 \%$ and $38,6 \%$ ). The first dimension, explaining $57 \%$ of the total variance, gathered the Kansei words related with Force and Snap Ratio. PC1 had a positive correlation with Snap Ratio and Pleasantness, and negative correlations with F1, F2 and force-related Kansei 


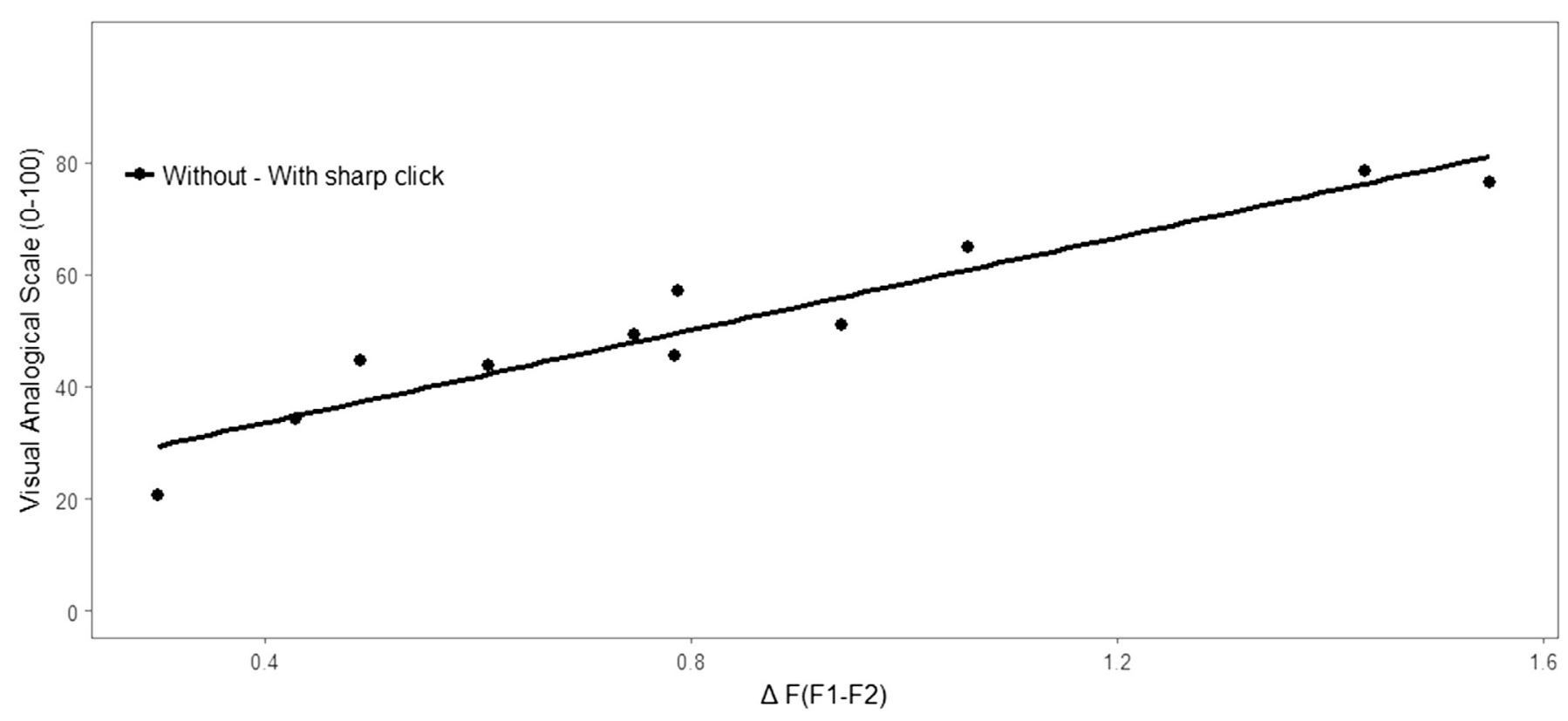

Fig. 8. Linear relation between $\Delta \mathrm{F}(\mathrm{F} 1-\mathrm{F} 2)$ and the perception of the Kansei "Without - With sharp click" $\left(R^{2}=.91\right)$.

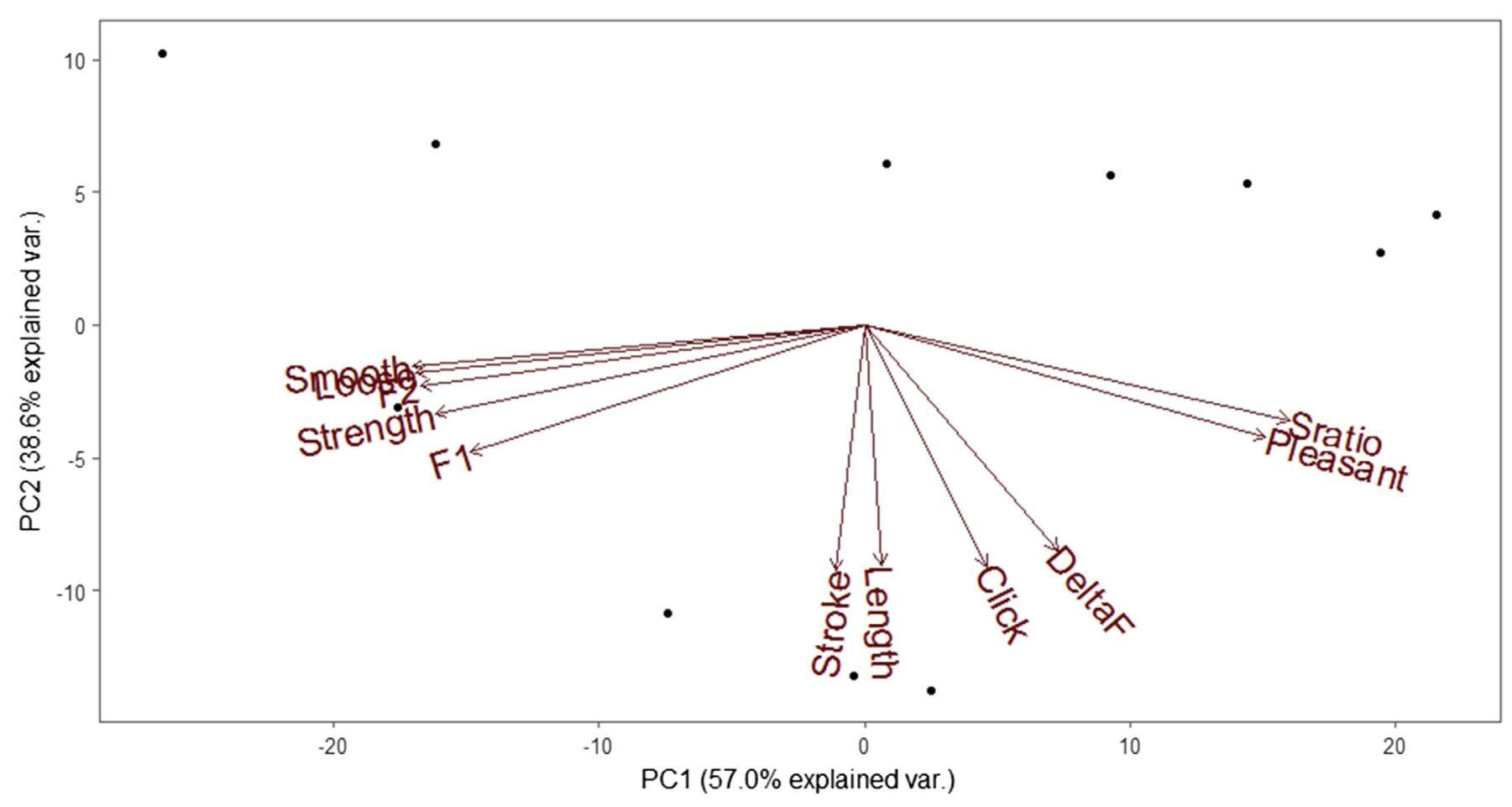

Fig. 9. Biplot from the PCA analysis grouping results in two main components: Force-related and Stroke-related.

words. Snap Ratio and Pleasantness had little correlation with Stroke and Length, and a positive correlation with Clickiness and $\Delta$ F. PC2 explained $38,6 \%$ of the total variance and was mainly influenced by Stroke and force related variables negatively affecting Stroke.

PC1 was called "Force" as it gathered all evaluations strongly connected with the variables F1 and F2 and the associated Kansei words. PC2 was called "Length" as it was mainly influenced by Stroke and associated stroke and force Kansei words.

\section{Discussion}

The main aim of this study was to apply the Kansei methodology to evaluate users' perceptions and sensations against the physical properties of keys. The implementation of this methodology will ultimately aid the industry in designing and constructing mechanical elements used in human-machine interfaces. It will be useful, for instance, in the design of keys in car radios and navigation systems.

Congruently with Kansei methodology, an evaluation protocol 
was designed, tested and applied to assess the perceptions of users of the properties of a set of keys. These keys varied in terms of force, stroke and snap ratio and were evaluated according to Strength, Robustness, Pleasantness, Smoothness, Looseness, Length and Clickiness.

The results demonstrated that participants clearly distinguished the physical properties of the keypads, assigning them with very distinct subjective properties. Both actuation force (F1) and contact force (F2) were predictors of the subjective perceptions of Strength, Robustness, Hardness and Stiffness. Results were also very consistent when the Kansei words under evaluation were more subjective, such as Clickiness and Pleasantness.

The variables F1 and F2 were predictors of the force-related Kansei, although F1 had stronger relations where F2 had weak, and vice-versa. Regarding the obtained results, F1 is a better predictor of strength and robustness, and F2 is a better predictor for Stiffness and Hardness. Thus, a robust, strong, hard and stiff key would be one with high values of F1 and F2.

Stroke was strongly related with the perception of length, as expected, but also with the perception of clickiness. Notwithstanding, this last Kansei was better predicted by a new parameter $\Delta \mathrm{F}$, the difference between F1 and F2. Further PCA analysis revealed it was clear that both Clickiness and $\Delta \mathrm{F}$ were close to the perception of Pleasantness of the key. Thus, it is possible to assume that a pleasant key is also one which has a large difference between F1 and F2, providing a sharper click. The strong relation found between the participants' evaluation and this physical variable, clearly suggests that in this study a more valid metric of Clickiness was found, than the Snap Ratio or Click Ratio, commonly referred in industrial manuals. Snap ratio was not a predictor of the sharpness of a click. Nevertheless, it proved to be a strong, and sole, predictor of Pleasantness. As the Snap Ratio increased, so did the perception of the Pleasantness of the key. Conversely, the perception of Stiffness and Smoothness decreased as snap ratio increased.

The results concerning Clickiness and Pleasantness confirm the general issues of the Snap Ratio parameter. It is not the case of being a bad parameter in predicting evaluations, but it has been used to evaluate the wrong dimension (Click) when in fact Snap Ratio should be used for more subjective evaluations such as Pleasantness.

A principal component analysis was performed to better understand which dimensions mediated the relations between the participant's evaluations and the physical properties. The analysis revealed two main components which were entitled "Force" and "Stroke". The "Force" dimension included all Kansei related with force, the independent variables F1 and F2, and the Snap Ratio and Pleasantness variables. The negative correlations between F1 and F2 and Snap Ratio-related variables indicate an inverse relation suggesting that the less the strength, the more pleasant a key is perceived. The "Stroke" component included the Stroke, Length and Clickiness variables as well as force-related variables.

A closer look at the results supports clear guidelines for a key that could be considered as pleasant. Based on our results, a pleasant key would have to have a F1 and F2 below the mean (in our case, below $2,6 \mathrm{~N}$ and $1,8 \mathrm{~N}$ ), a stroke length above the mean $(1,29 \mathrm{~mm}), \mathrm{a} \Delta \mathrm{F}$ above $0,83 \mathrm{~N}$ and finally, a Snap Ratio value above the mean (35\%). It is important to note, however, that the values of F1 and F2 are not so important in themselves when referring to the perception of Pleasantness, as it is the difference between them. These results meet some of the recommendations for typical keyboards of Abatek, a manufacturer and supplier of silicone keypads: Force between 1.5 and $2.5 \mathrm{~N}$, Stroke of $1 \mathrm{~mm}$ and a Snap Ratio between 25 and 35\%. For Abatek, a higher Stroke (1.5 mm) and Snap Ratio (>35\%) should be reserved for critical keys.

\section{Conclusion}

This study demonstrated the robustness of the Kansei method, as all participants were sensitive to the chosen Kansei Words. Furthermore, it was evident that subjective perceptions are clearly related to certain physical traits.

The perceptions of Strength, Robustness, Looseness and Smoothness were all predicted by both F1 and F2. Length and Clickiness were predicted by stroke, and Pleasantness was predicted by the snap ratio. It can be considered that the most surprising results belonged to the Snap Ratio parameter. Even though its conceptual definition is related with the sensation of a click, in the present study, only Stroke was the predictive variable for the perception of the sharpness of a click, contradicting some industry design guides (ARC-USA, 2009) while being in line with previous Kansei Engineering studies (Hatzfeld et al., 2010). Our findings motivated further explorations of the forces implicated in the Snap Ratio. Thus, the sensation of Clickiness was better predicted by the value of the $\Delta \mathrm{F}$, which is the difference between F1 and F2. Our results suggest $\Delta \mathrm{F}$ as a better metric for the evaluation of the sharpness of the click of a key, than the Snap Ratio or Click Ratio.

Snap ratio turned out to be a good predictor of how pleasant or unpleasant a key can be. The results point towards the conclusion that a good key is the one with a high Snap Ratio, meaning that the difference between F1 and F2 must be high, with a high stroke and above the mean values of F1 and F2.

The application of the Kansei method led to some suggestions of how to improve the construction and consequent interaction with rubber keypads. It also provides information for the construction of other evaluation protocols which can be applied to test the most desirable subjective experiences for future products. Considering the difficulty of training collaborators and assessing their ability in manual evaluating errors in keys and buttons, having a somewhat automated tool would be a major advantage.

The Kansei method has shown extremely strong relations between subjective perceptions and physical properties. Consequently, further studies using this methodology applied to car simulators using different in-vehicle interfaces, and later, in real vehicles, have the potential to yield valuable results in regard to the subjective experience of the end-users of these products. The evermore immersive experience could affect the interaction experience when the Kansei method is applied in a realistic environment.

In spite of the results, a limitation of the present study might be the balance of the sample, namely as far as gender and age are concerned. As such, future studies using Kansei methodology should aim for larger and more representative samples in order to obtain more robust results.

The results gathered in this experiment will be used to set up a list of requirements and guidelines for the construction and evaluation of rubber keypads. The Kansei method will also be implemented in future developments such as the evaluation of head-up displays image distortions and the evaluation of tactile feedback in haptic interfaces. To understand which property affects which subjective dimension means better products and an enhancement of the whole customer experience.

\section{Acknowledgements}

All authors would like to particularly thank the collaboration of Catarina Neto, João Lamas and João Pedro Ferreira.

This research was supported by the project HMIExcel - I\&D crítica em torno do ciclo de desenvolvimento e produção de soluções multimédia avançadas para automóvel/Critical R\&D in the framework of the development and production cycle of advanced 
multimedia solutions for automobile (AICEP-PIN-HMIEXCEL).

\section{References}

ARC-USA, 2009. Keypads Design Guide [WWW Document]. Gd. Prairie, TX, 2009. Bijur, P.E., Silver, W., Gallagher, E.J., 2001. Reliability of the visual analog scale for measurement of acute pain. Acad. Emerg. Med. 8, 1153-1157. http://dx.doi.org 10.1111/j.1553-2712.2001.tb01132.x.

Dahlgaard, J.J., Schutte, S., Ayas, E., Dahlgaard-Park, S.M., 2008. Kansei/affective engineering design. TQM J. 20, 299-311. http://dx.doi.org/10.1108/ 17542730810881294.

DeLoach, L.J., Higgins, M.S., Caplan, a B., Stiff, J.L., 1998. The visual analog scale in the immediate postoperative period: intrasubject variability and correlation with a numeric scale. Anesth. Analg. 86, 102-106. http://dx.doi.org/10.1097/ 00000539-199801000-00020.

Dewey, J., 2005. Art as Experience. Penguin, Chicago.

Hatzfeld, C., Kern, T. a., Werthschützky, R., 2010. Improving the prediction of haptic impression user ratings using perception-based weighting methods: experimental evaluation. Lect. Notes Comput. Sci. Incl. Subser. Lect. Notes Artif. Intell. Lect. Notes Bioinforma. 6191 LNCS 93-98. http://dx.doi.org/10.1007/978-3-64214064-8_14.

Jindo, T., Hirasago, K., 1997. Application studies to car interior of Kansei engineering Int. J. Ind. Ergon. 19, 105-114. http://dx.doi.org/10.1016/S0169-8141(96)000078.

Kosaka, H., Nishitani, H., Watanabe, K., 2005. Estimation of reaction force of a keyboard switch based on Kansei information using neural networks. 2005 IEEE Networking. Sens. Control. ICNSC2005-Proc. 2005, 425-430. http://dx.doi.org/ 10.1109/ICNSC.2005.1461228.

Lee, K.K., Kim, T.Y., Lee, M.G., Han, S.H., 2015. Robust optimization of the rubber domes by using 9 level orthogonal array and sensitivity constraints. In: 3rd International Conference on Materials and Reliability. Jeju, pp. 5-6.

Liu, Y., 2003. Engineering aesthetics and aesthetic ergonomics: theoretical foundations and a dual-process research methodology. Theor. Issues Ergon. Sci. 46 1273-1292. http://dx.doi.org/10.1080/00140130310001610829.
Nagamachi, M., 2005. Kansei engineering. In: Stanton, N., Hedge, A., Brookhuis, K. (Eds.), Handbook of Human Factors and Ergonomics Methods. CRC Press, Florida, 83-I-83-IV.

Nagamachi, M., Lokman, A., 2010. Innovations of Kansei Engineering. CRC Press.

Nordvik, E., Schütte, S., Broman, N.O., 2009. People's perceptions of the visual appearance of wood flooring: a Kansei engineering approach. For. Prod. J. 59, 67-74. http://dx.doi.org/10.13073/0015-7473-59.11.67.

Norman, D.A., 2004. Emotional Design. Basic Books.

Osgood, C.E., Suci, G.J., Percy, H.T., 1957. The Measurement of Meaning. University of Illinois Press., Urbana.

Rösler, F., Battenberg, G., Schüttler, F., 2009. Subjective perceptions and objective characteristics of control elements. ATZautotechnology 9, 48-53.

Schütte, S., 2002. Designing Feelings into Products: Integrating Kansei Engineering Methodology in Product Development. Linköpings Universitet Printings.

Schütte, S., 2005. Engineering Emotional Values in Product Design -Kansei Engineering in Development. Diss. 951. Linköpings Universitet.

Schütte, S., 2013. Evaluation of the affective coherence of the exterior and interior of chocolate snacks. Food Qual. Prefer 29, 16-24. http://dx.doi.org/10.1016/ j.foodqual.2013.01.008.

Schütte, S., Eklund, J., 2005. Design of rocker switches for work-vehicles - an application of Kansei Engineering. Appl. Ergon. 36, 557-567. http://dx.doi.org/ 10.1016/j.apergo.2005.02.002.

Tanoue, C., Ishizaka, K., Nagamachi, M., 1997. Kansei Engineering: a study on perception of vehicle interior image. Int. J. Ind. Ergon. 19, 115-128. http:// dx.doi.org/10.1016/S0169-8141(96)00008-X.

Vu, K., Proctor, R., 2011. Handbook of Human Factors in Web Design.

Wellings, T., Williams, M., Tennant, C., 2010. Understanding customers' holistic perception of switches in automotive human-machine interfaces. Appl. Ergon. 41, 8-17. http://dx.doi.org/10.1016/j.apergo.2009.03.004.

Wright, Peter, Mccarthy, L.M., John, 2005. Making sense of experience. In: Mark, A. Blythe, Kees, Overbeeke, Andrew, F., Monk, P.C.W. (Eds.), Funology. From Usability to Enjoyment. Springer Science + Business Media, Inc., pp. 43-53

Yang, S., Nagamachi, M., Lee, S., 1999. Rule-based inference model for the Kansei engineering system. Int. J. Ind. Ergon. 24, 459-471. http://dx.doi.org/10.1016/ S0169-8141(98)00040-7. 